\title{
Manganese dioxide-modified carbon paste electrode for voltammetric determination of riboflavin
}

\author{
Eda Mehmeti ${ }^{1}$ - Dalibor M. Stanković ${ }^{2} \cdot$ Sudkate Chaiyo $^{3}$ - Lubomir Švorc ${ }^{4}$. \\ Kurt Kalcher $^{1}$
}

Received: 15 November 2015 / Accepted: 9 February 2016 /Published online: 29 February 2016

(C) The Author(s) 2016. This article is published with open access at Springerlink.com

\begin{abstract}
A carbon paste electrode bulk was modified with $\mathrm{MnO}_{2}$ and investigated for use as an electrochemical sensor for riboflavin (vitamin $\mathrm{B}_{2}$ ) using differential pulse voltammetry (DPV). Riboflavin displays a well expressed oxidation peak at $-0.15 \mathrm{~V}$ (versus $\mathrm{Ag} / \mathrm{AgCl}$ ) in solutions with a $\mathrm{pH}$ value of 2 . Effects of $\mathrm{pH}$ value, pulse amplitude and pulse time were optimized by employing DPV. The signals obtained are linearly related to the concentrations of riboflavin in the range from 0.02 to $9 \mu \mathrm{M}$. Other features include a $15 \mathrm{nM}$ detection limit, and good reproducibility $( \pm 3 \%)$ and repeatability $( \pm 2 \%)$. Interferences by common compounds were tested, and the method was successfully applied to the determination of riboflavin in pharmaceutical formulations where is gave recoveries in the range from 95 to $97 \%$.
\end{abstract}

Keywords Differential pulse voltammetry $\cdot$ Cyclic voltammetry $\cdot$ Vitamin $B_{2} \cdot$ Electrooxidation

Eda Mehmeti

eda.mehmeti@edu.uni-graz.at

1 Institute of Chemistry, Analytical Chemistry, Karl-Franzens University, 8010 Graz, Austria

2 Department of Analytical Chemistry, Innovation Center of the Faculty of Chemistry, University of Belgrade, Studentski trg 12-16, Belgrade 11000, Serbia

3 Electrochemistry and Optical Spectroscopy Research Unit, Department of Chemistry, Faculty of Science, Chulalongkorn University, 254 Phayathai Road, Pathumwan, Bangkok 10330, Thailand

4 Institute of Analytical Chemistry, Faculty of Chemical and Food Technology, Slovak University of Technology in Bratislava, Radlinského 9, SK-812 37 Bratislava, Slovak Republic

\section{Introduction}

Vitamins are the important group of organic compounds and they are necessary for human health. They are required in the diet and to human body for normal growth and nutrition where their absence can lead to many diseases [1]. Riboflavin or Vitamin $B_{2}$ is a water soluble vitamin and an essential component of flavoenzymes which plays a significant role in biochemical reactions of the human body [2]. It cannot be synthesized in human body therefore has to be obtained dietary from the sources such as liver, cheese, milk, meat, eggs, wines, and tea [3] therefore its insufficiency is associated with eye lesions and skin disorders [4].

Up to the date several analytical methods are used for the determination of Vitamin $B_{2}$ such as HPLC [5] chemiluminescence [6], fluorescence [7] and capillary electrophoresis [8]. These methods provide highly sophisticated instrumentation setup and they are more time consuming [9]. Therefore, electrochemical methods have received great attention due to their simple, sensitive, low cost and rapid response time [10-12]. The use of chemically modified electrodes offers a tool for improving the performance of electrodes and several functional materials are used as a modifier for vitamin sensors $[13,14]$.

Carbon paste electrodes (CPE) are widely used as an electrode material for the development of various electrochemical sensors and biosensors and they can be simply modified [15]. The main advantages of carbon paste electrode are due to easy way of preparation, the new reproducible surface and low residual current in wide potential windows [16]. The modification of carbon paste electrodes with catalytic metals, has received also considerable attention [11]. There are already reported several carbon electrodes with numerous types of modifiers such as $\mathrm{MnO}_{2}, \mathrm{Fe}_{3} \mathrm{O}_{4}, \mathrm{FeO}, \mathrm{SnO}_{2}, \mathrm{CuO}, \mathrm{Fe}_{2} \mathrm{O}_{3}$ which are found to be very sensitive to acids and basis media, oxides of platinum group metals, complexes of copper, nickel, 
iron and chromium or/and also nanocomposites of these modifiers. The purpose of the use of these modifiers is due to the lowering overpotential for the oxidation or reduction of analytes, in comparison with unmodified electrodes. The obtained analytical responses are significantly higher and with high reproducibility of the electrode performance. $\mathrm{MnO}_{2}$ based electrodes are very popular for all mentioned characteristics with high catalytic effect at an appropriate potential for sensing the target analyte [17]. The aim of this work was to find a simple and cheap procedure for the determination of Vitamin $\mathrm{B}_{2}$ at low concentrations based on a manganese dioxide bulk-modified carbon paste electrode $\left(\mathrm{MnO}_{2} / \mathrm{CPE}\right)$.

\section{Experimental}

\section{Chemicals}

Boric acid, sodium hydroxide, acetic acid, phosphoric acid and manganese(IV) oxide (99.99\%, diameter approximately $5 \mu \mathrm{m}$ ), were purchased from Sigma-Aldrich (https://www. sigmaaldrich.com/) and used as received without any further purification. Calibration solutions were prepared from the stock solution $(1 \mathrm{mM})$ by appropriate dilution with supporting electrolyte. Britton-Robinson buffer was prepared in usual way by mixing of $40 \mathrm{mM}$ of all necessary components (phosphoric acid, acetic acid and boric acid). The $\mathrm{pH}$ of different Britton-Robinson buffer was adjusted with sodium hydroxide (0.2 M).

Working solutions of vitamin $\mathrm{B}_{2}\left(\mathrm{VB}_{2}\right)$ were freshly prepared on the day of the experiment by appropriate dilution with the supporting electrolyte. All other chemicals were of analytical reagent grade. Deionized water with a resistivity of $18 \mathrm{M} \Omega \mathrm{cm}$ (Millipore Milli-Q system) was used for the preparation of all the solutions.

\section{Apparatus}

Cyclic voltammetric (CV) measurements and differential pulse voltammetric (DPV) measurements were performed using an Autolab PGSTAT $302 \mathrm{~N}$ (http://www.metrohm. com/de-at) potentiostat/galvanostat controlled by corresponding software (Nova 1.10). The electrochemical cell (total volume of $10 \mathrm{~mL}$ ) consisted of a glass vessel equipped with the $\mathrm{Ag} / \mathrm{AgCl}(3 \mathrm{M} \mathrm{KCl}$, Metrohm 6.0733.100) as a reference electrode, platinum wire as a auxiliary electrode and carbon paste as a working electrode. All of the $\mathrm{pH}$ values were measured using a $\mathrm{pH}$ meter (Orion, model 1230 ) with a combined electrode (glass-reference electrodes), which was calibrated weekly with standard buffer. All potentials given in the text are versus the $\mathrm{Ag} / \mathrm{AgCl}$ reference electrode at room temperature.

\section{Preparation of a carbon electrode modified with manganese dioxide $\left(\mathrm{MnO}_{2} / \mathrm{CPE}\right)$}

Plain carbon paste was prepared by carefully hand mixing $380 \mu \mathrm{L}$ of paraffin oil with $1 \mathrm{~g}$ of graphite powder in a mortar with a pestle. After standing overnight a portion of the resulting paste was packed into the end of a Teflon tube (an inner diameter $5 \mathrm{~mm}$, outer diameter $10.15 \mathrm{~mm}$ ) and the surface was polished using a PTFE plate or wet filter paper. The carbon paste was modified by adding $5 \%(\mathrm{~m} / \mathrm{m})$ of $\mathrm{MnO}_{2}$ as received. The amount of modifier was selected according to our experience and previously described articles, where it is found that modification with $5 \%$ of $\mathrm{MnO}_{2}$ gives best analytical response [11].

Whenever regeneration was required, a layer of the surface was removed and replaced by fresh paste. Electrical contact was made with a copper wire through the center of the tube.

\section{Procedures}

Cyclic voltammetry with a scan rate of $0.1 \mathrm{~V} / \mathrm{s}$ (if not stated otherwise) was used for characterizing the electrochemical behavior of the analyte at the unmodified and modified electrode surface. The investigated solutions were transferred into the voltammetric cell and the voltammograms (usually 5 cycles) were recorded in a potential range between $-0.5 \mathrm{~V}$ and $+0.5 \mathrm{~V}$.

Differential pulse voltammetry with optimized parameters in the potential range from $-0.5 \mathrm{~V}$ to $+0.3 \mathrm{~V}$ (pulse amplitude of $0.12 \mathrm{~V}$ and pulse time of $0.04 \mathrm{~s}$ ) was used for the quantification of $\mathrm{VB}_{2}$.

\section{Interference studies}

Oxidation behavior of some possible interferences such as vitamins $\mathrm{B}_{1}, \mathrm{~B}_{6}$ and $\mathrm{B}_{12}$, ascorbic acid and glucose, were

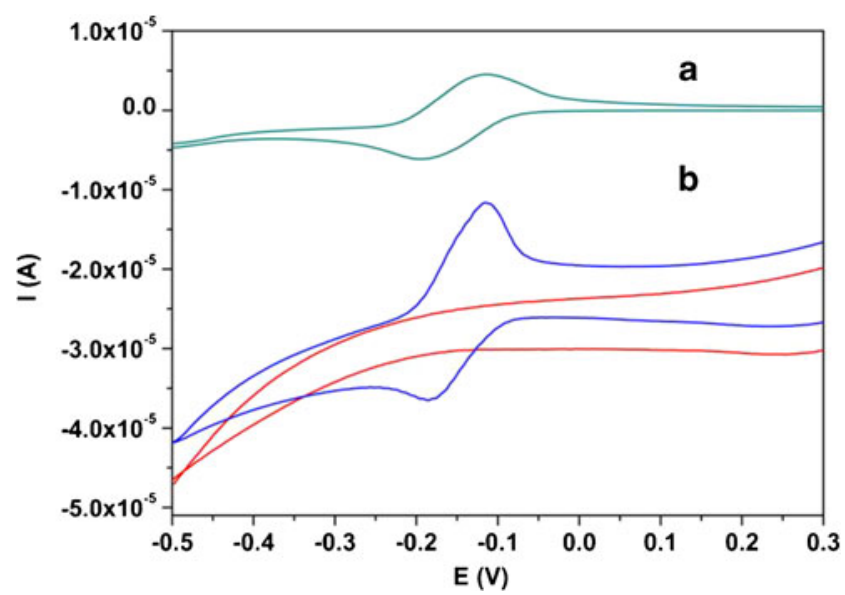

Fig. 1 Cyclic voltammograms of $0.1 \mathrm{mM}$ Vitamin $\mathrm{B}_{2}$ on $\left.\mathrm{A}\right) \mathrm{CPE}$ unmodified and $\mathrm{B}$ ) $\mathrm{MnO}_{2} / \mathrm{CPE}$ in buffer at $\mathrm{pH} 2.0$, scan rate of $0.1 \mathrm{~V} \cdot \mathrm{s}^{-1}$ 


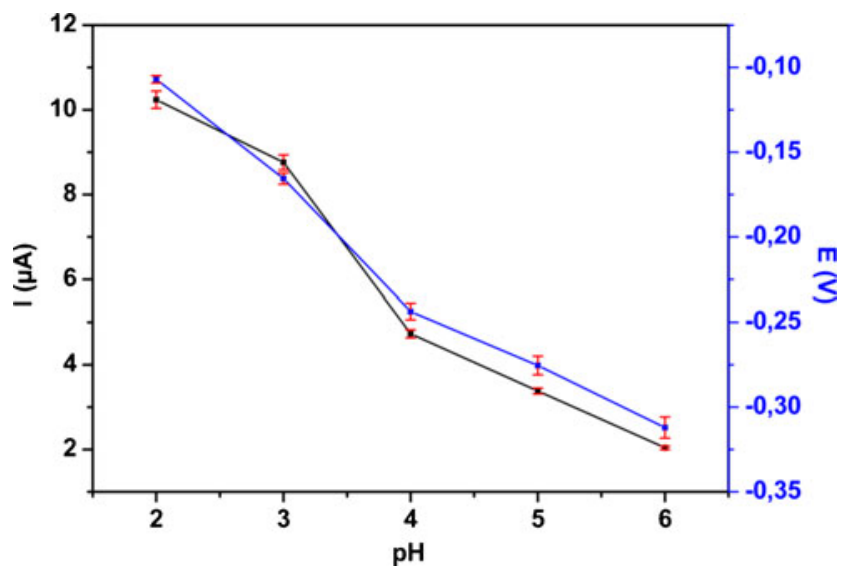

Fig. 2 Effect of pH on the peak potential ( $\mathbf{})$ and peak current ( $\mathbf{\square})$ of $0.1 \mathrm{mM}$ Vitamin $\mathrm{B}_{2}$ in buffer at $\mathrm{pH} 2.0$ on $\mathrm{MnO}_{2} / \mathrm{CPE}$ using $\mathrm{CV}$ at scan rate of $0.1 \mathrm{~V} \cdot \mathrm{s}^{-1}$

tested in concentrations of $1 \mu \mathrm{M}$ under optimized experimental conditions. The changes of the peak current of $1 \mu \mathrm{M} \mathrm{VB}_{2}$ were compared in the absence and in the presence of selected interferences. It was considered that tested compounds strongly interfere with the determination of riboflavin if gives signal changes more than $\pm 10 \%$.

\section{Sample analysis}

Vitamin $\mathrm{B}_{2}$ tablets $(4.55 \mathrm{~g})$ were dissolved in $10 \mathrm{~mL}$ of water and an aliquot $(10 \mu \mathrm{L})$ was added to $10 \mathrm{~mL}$ of buffer at $\mathrm{pH} 2.0$ and recorded by DPV under optimized experimental conditions. The concentration of $\mathrm{VB}_{2}$ was evaluated from calibration curve. All experiments were performed in triplicate.

\section{Results and discussion}

\section{Electrochemical behavior of vitamin $\mathrm{B}_{2}$ on $\mathrm{MnO}_{2} / \mathrm{CPE}$}

Cyclic voltammetry was applied to study the electrochemical behavior of $\mathrm{VB}_{2}$ on a $\mathrm{MnO}_{2} / \mathrm{CPE}$. All necessary factors influencing the current response of $\mathrm{VB}_{2}$ were carefully studied to explore the best conditions at which the best analytical performance was achieved. The electrochemical behavior of the $\mathrm{MnO}_{2} / \mathrm{CPE}$ towards $\mathrm{VB}_{2}$ was compared to the unmodified CPE electrode (Fig. 1).

The unmodified CPE (A) gave a small current response with well-defined oxidation peak at around $-0.15 \mathrm{~V}$ and reduction peak at around $-0.2 \mathrm{~V}$. The modified electrode CPE $/ \mathrm{MnO}_{2}$ (B) gives a well manifested oval-shape signal response at $-0.15 \mathrm{~V}$ in the anodic direction. In the reverse scan also the reduction is observable at around $-0.2 \mathrm{~V}$ indicating that the oxidation and reduction of the analyte during the reaction is electrochemically reversible. It is noted that the current corresponding to $\mathrm{MnO}_{2} / \mathrm{CPE}$ electrode is at about two time higher value when compared to the unmodified electrode. This is mainly attributed to the higher active surface area of $\mathrm{MnO}_{2}$ particles present on the surface of modified CPE electrodes. The current response obtained for the modified electrode approves the effect of $\mathrm{MnO}_{2}$ in the electrode structure.

\section{Effect of pH value of supporting electrolyte}

Effect of $\mathrm{pH}$ on peak current and peak potential was investigated in the range from 2 to 6 using buffer. The peak current decreased considerably beyond $\mathrm{pH} 2.0$. The peak potential of $\mathrm{VB}_{2}$ was shifted to more negative potentials linearly with increasing of the $\mathrm{pH}$ of supporting electrolyte. Based on these
Fig. 3 Cyclic voltammograms of $0.1 \mathrm{mM}$ Vitamin $\mathrm{B}_{2}$ in buffer at $\mathrm{pH} 2.0$ on $\mathrm{MnO}_{2} / \mathrm{CPE}$ at various scan rates from $0.01 \mathrm{~V} \cdot \mathrm{s}^{-1}$ to $0.5 \mathrm{~V} \cdot \mathrm{s}^{-1}$. The peak current (Ip) as a function of $\mathrm{v}^{1 / 2}$ for the oxidation peak of Vitamin $B_{2}$ is shown in the inset

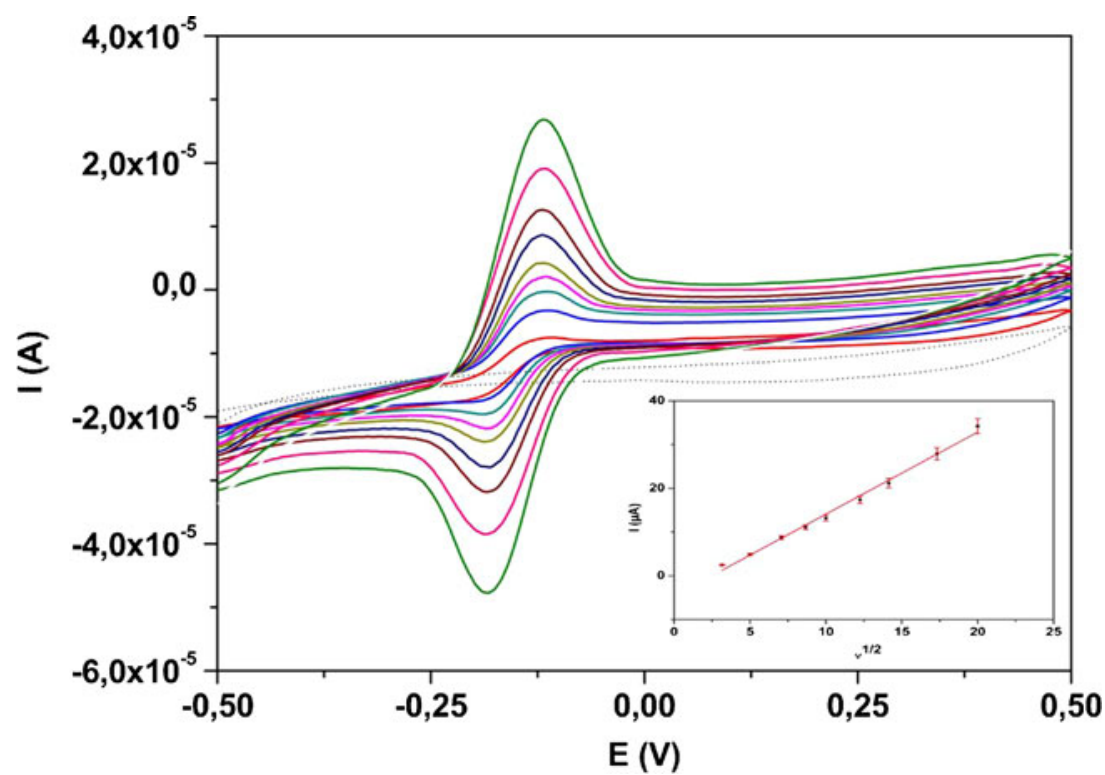




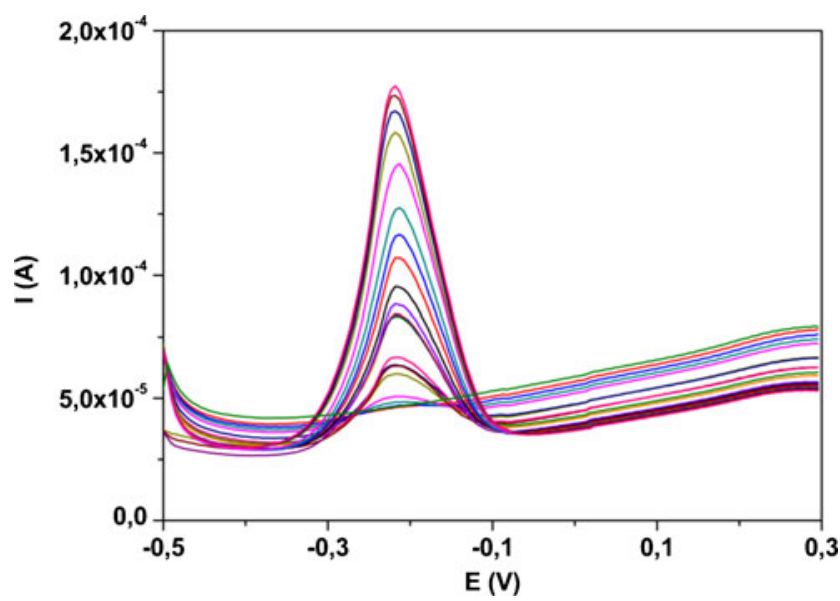

Fig. 4 DP voltammograms for different concentrations of Vitamin $\mathrm{B}_{2}$ from 0.02 to $9 \mu \mathrm{M}$ in buffer at $\mathrm{pH} 2.0$ on $\mathrm{MnO}_{2} / \mathrm{CPE}$ at optimized DPV parameters

facts $\mathrm{pH} 2.0$ was chosen for further experiments. When considering $\mathrm{pH}$ from 2 to 6 the peak potential shift to the more negative values occurs with the corresponding equation $E p$ $(V)=-0.052 \times p H-0.01272$.

The slope of $52 \mathrm{mV}$ per $\mathrm{pH}$ unit is close to the ideal value of $59 \mathrm{mV}$ which might indicate that the number of protons and electrons involved in the electrochemical reaction is in the ratio 1:1. In Fig. 2 the dependence of the peak current (Ip) and of the peak potential (Ep) on the $\mathrm{pH}$ of buffer is represented. Obtained proton/electron ratio is same as those previously described in the literature and in accordance with the oxidation reaction of riboflavin where two electrons and two protons are involved.

\section{Effect of scan rate}

In order to study the nature of the electrochemical reaction of $\mathrm{VB}_{2}$ on $\mathrm{MnO}_{2} / \mathrm{CPE}$ the effect of different scan rate in the range from $0.01 \mathrm{~V} \cdot \mathrm{s}^{-1}$ to $0.5 \mathrm{~V} \cdot \mathrm{s}^{-1}$ on the peak current and peak potential was investigated by CV (Fig. 3) in buffer at $\mathrm{pH}$ 2.0. The peak current of $\mathrm{VB}_{2}$ increased practically linearly with square root of the scan rate indicating that the oxidation and reduction process on the electrode surface is controlled by diffusion rather than by adsorption. Inset of Fig. 3 the linear dependence can be expressed by the equation: Ip $(\mu \mathrm{A})=1.8760 \times v^{1 / 2}\left(\mathrm{mV} \cdot \mathrm{s}^{-1}\right)-4.662\left(\mathrm{R}^{2}=0.9927\right)$. Increase of the scan rate does not cause significant changes in redox peak potentials $(\Delta \mathrm{Ep} \sim 70 \mathrm{mV})$. These results indicate reversible process for the nature of electrochemical reaction.

\section{Optimization of DPV parameters}

For the quantitative determination of $\mathrm{VB}_{2}$, DPV was used as a suitable electroanalytical technique due to the low background currents and low detection limits. The parameters for DPV such as pulse amplitude and pulse time were optimized to find the best experimental setup for the quantification of $\mathrm{VB}_{2}$. The optimization was carried out in previously selected buffer at $\mathrm{pH} 2.0$ with the concentration of $0.1 \mathrm{mM} \mathrm{VB}_{2}$. During this optimization procedure one investigated parameter was varied while the others were kept fixed. When the pulse time was varied from 0.01 to $0.1 \mathrm{~s}$, the peak current increased up to value of $0.04 \mathrm{~s}$ and with further increase of the pulse time obtained current was decreasing. The most appropriate peak currents was observed at $0.04 \mathrm{~s}$. Varying the pulse amplitude in the range of $0.01-$ $0.35 \mathrm{~V}$ the peak currents increased with concomitant broadening of the peaks; finally a value of $0.12 \mathrm{~V}$ of pulse amplitude was chosen which was found to be most appropriate with respect to the current response and peak shape of $\mathrm{VB}_{2}$. All other experiments such as interference studies, calibration curve and sample analysis were carried out under these optimized parameters.

\section{Analytical performance}

Calibration curve for determination of $\mathrm{VB}_{2}$ on $\mathrm{MnO}_{2} / \mathrm{CPE}$ was obtained using DPV under the optimized experimental conditions and was constructed by plotting estimated oxidation peak current versus known $\mathrm{VB}_{2}$ concentrations. Figure 4 shows a typical DP voltammograms obtained for different concentrations of $\mathrm{VB}_{2}$. The obtained currents were linear with logarithm of concentration in the range from 0.02 to $9 \mu \mathrm{M}$.

The graph shows a dynamic range for concentrations from 0.02 to $9 \mu \mathrm{M}$, with a corresponding linear equation: $I$ $(\mu \mathrm{A})=55.51723 \times \log _{C} \mu \mathrm{M}+92.31389$. Correlation coefficient of $R^{2}$ is equal to 0.9976 . The detection limit $\left(3 \sigma_{c=0.06 \mu M} /\right.$

Table 1 Recently reported electrodes for the determination of riboflavin

\begin{tabular}{|c|c|c|c|c|c|}
\hline Electrode & Modifier & Method & Limit of Detection & Linear Range & Ref. \\
\hline Gold Electrode & $\begin{array}{l}\text { homoadenine single-stranded DNA/ } \\
\text { molybdenum } \\
\text { disulfide-graphene nanocomposite }\end{array}$ & DPV & $20 \mathrm{nM}$ & $0.025-2.25 \mu \mathrm{M}$ & [18] \\
\hline Carbon-paste electrode & zeolite & $\mathrm{CV}$ & $0.71 \mu \mathrm{M}$ & $1.7-34 \mu \mathrm{M}$ & [19] \\
\hline Copper & Bi-film & SWAdSV & $100 \mathrm{nM}$ & $0.3-0.8 \mu \mathrm{M}$ and $1.0-9.0 \mu \mathrm{M}$ & {$[2]$} \\
\hline Pencil graphite electrode & DNA & DPV & $0.9 \mu \mathrm{M}$ & $1-186 \mu \mathrm{M}$ & {$[20]$} \\
\hline Carbon paste & $\mathrm{MnO}_{2}$ & DPV & $15 \mathrm{nM}$ & 0.02 to $9 \mu \mathrm{M}$ & This work \\
\hline
\end{tabular}


Table 2 Results for determination of $\mathrm{VB}_{2}$ in pharmaceutical formulations

\begin{tabular}{|c|c|c|c|c|c|c|c|c|}
\hline Sample/Tablet & Labeled/ $\mu \mathrm{M}$ & Found/ $/ \mu \mathrm{M}$ & Added(S1)/ $/ \mathrm{M}$ & Found(S1)/ $/ \mu \mathrm{M}$ & Recovery $/ \%$ & Added(S2)/ $/ \mathrm{M}$ & Found $(\mathrm{S} 2) / \mu \mathrm{M}$ & Recovery $/ \%$ \\
\hline & 0.24 & 0.26 & 0.10 & 0.35 & 97 & 0.2 & 0.53 & 95 \\
\hline
\end{tabular}

slope) was estimated as $15 \mathrm{nM}$. The repeatability ( $n=4$ measurements, $\mathrm{c}=0.06 \mu \mathrm{M} \mathrm{VB}_{2}$ ) was calculated as $\pm 2 \%$. RSD, and the reproducibility of the electrode preparation, based on measurements of the $0.06 \mu \mathrm{M}$ of $\mathrm{VB}_{2}$ with four separately prepared electrodes, was estimated to be $\pm 3 \%$, which improves our statement that this electrode can be satisfactory replacement for commercial electrodes.

This sensor offers low detection limit, wide linear range with a good sensitivity and reproducibility and in comparison with previously reported data this sensor possess comparable or better characteristics for the quantification of $\mathrm{VB}_{2}$.

Table 1 shows a comparison of the $\mathrm{MnO}_{2} / \mathrm{CPE}$ with other electrodes described recently in the literature. The method presented in this work has a comparable or better performance with wide linear range and low detection limit. The advantages of our method are based on simplicity of the electrode preparation.

\section{Interference studies}

In order to evaluate the selectivity of the method toward $\mathrm{VB}_{2}$, the effect of possible interfering agents was investigated under optimized conditions. Some possible interfering compounds were tested, such as vitamin $\mathrm{B}_{1}, \mathrm{~B}_{6}, \mathrm{~B}_{12}$, ascorbic acid and glucose. These compounds in concentration of $1 \mu \mathrm{M}$, in absence of $\mathrm{VB}_{2}$, practically do not provide electrochemical activity in the tested potential range (Fig. 5 a). The presence of these interferences in same concentration level as $\mathrm{VB}_{2}(1 \mu \mathrm{M})$ do not causes changes in the peak current obtained for $\mathrm{VB}_{2}$ (Fig. 5 b). Hydrogen peroxide, dopamine and uric acid can be

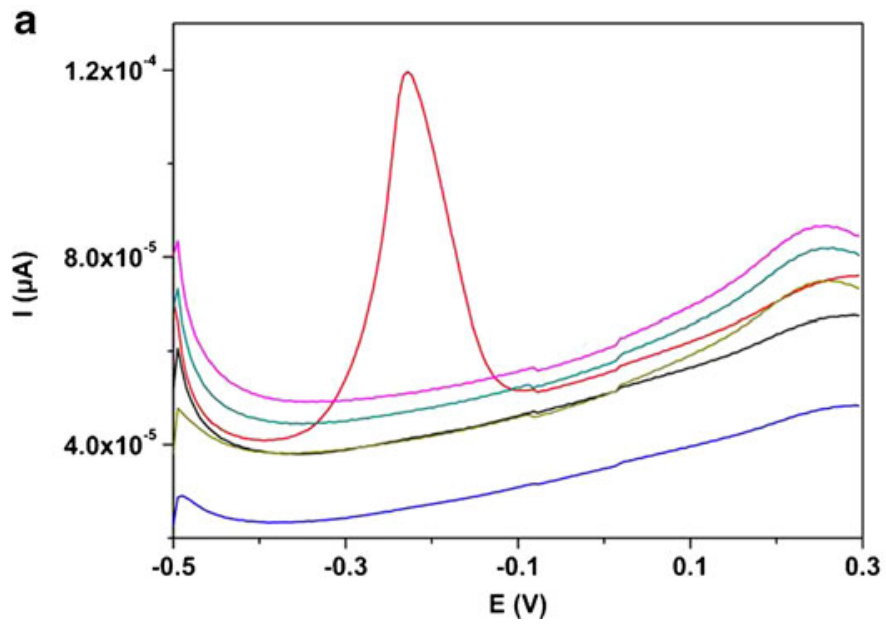

Fig. 5 a DPVs of all tested compounds in concentration of $1 \mu \mathrm{M}$ in absence of $\mathrm{VB}_{2}$ and $\mathbf{b}$ Signals of tested compounds in the presence of expected as possible interferences in the human body fluid samples (urine and blood serum). According previously published data $[11,21,22]$ in strongly acidic media these compounds provides oxidation peaks at higher potentials compared to $\mathrm{VB}_{2}(\sim-0.2 \mathrm{~V})$. Based on these results this method has a good selectivity for the electrochemical determination of $\mathrm{VB}_{2}$.

\section{Analytical application}

To test the practical applicability of the method it was applied for the analysis of $\mathrm{VB}_{2}$ content in the pharmaceutical formulations. The content of $\mathrm{VB}_{2}$ was determined from the calibration curve by optimized DPV method. The samples were prepared as it is previously described. The mean value of the concentration obtained by the calibration curve as $0.24 \mu \mathrm{M}$ corresponds quite well to the labeled value of the commercial pharmaceutical formulation $0.26 \mu \mathrm{M}$. Standard addition of different amount of $\mathrm{VB}_{2}$ caused current increments at the sample potential (Fig. 6) which allows the evaluation of the recovery values.

The found values are in good agreement with added amount of $\mathrm{VB}_{2}$ and the accuracy was evaluated with recovery experiments (Table 2). The results are confirming that the sensor was applied for the determination of the concentration of $\mathrm{VB}_{2}$ in pharmaceutical formulations.

\section{Conclusions}

Carbon paste electrode modified with manganese dioxide was described for the determination of the vitamin $\mathrm{B}_{2}$ by differential

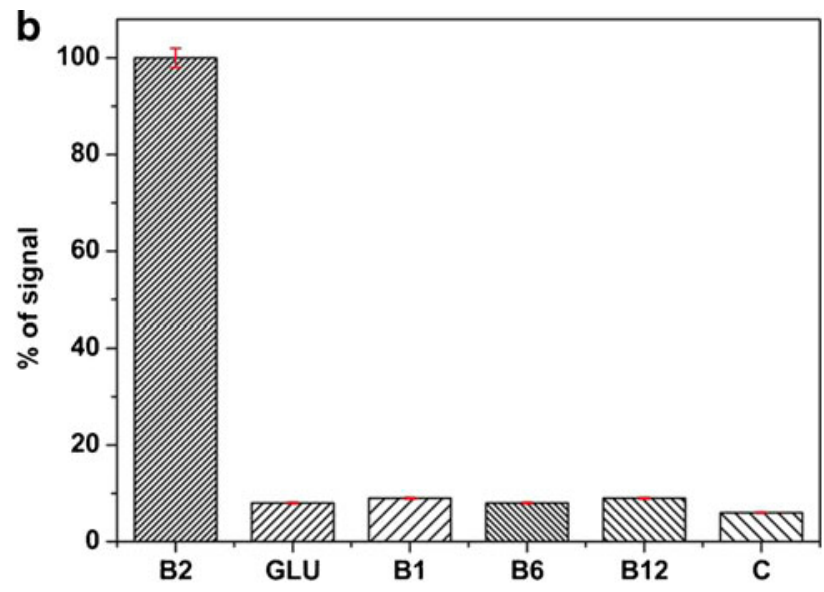

$1 \mu \mathrm{M} \mathrm{VB}_{2}$, expressed as relative signals of $\mathrm{VB}_{2}$ on $\mathrm{MnO}_{2} / \mathrm{CPE}$ in buffer at $\mathrm{pH} 2.0$ at scan rate of $0.1 \mathrm{~V} \cdot \mathrm{s}^{-1}$ 


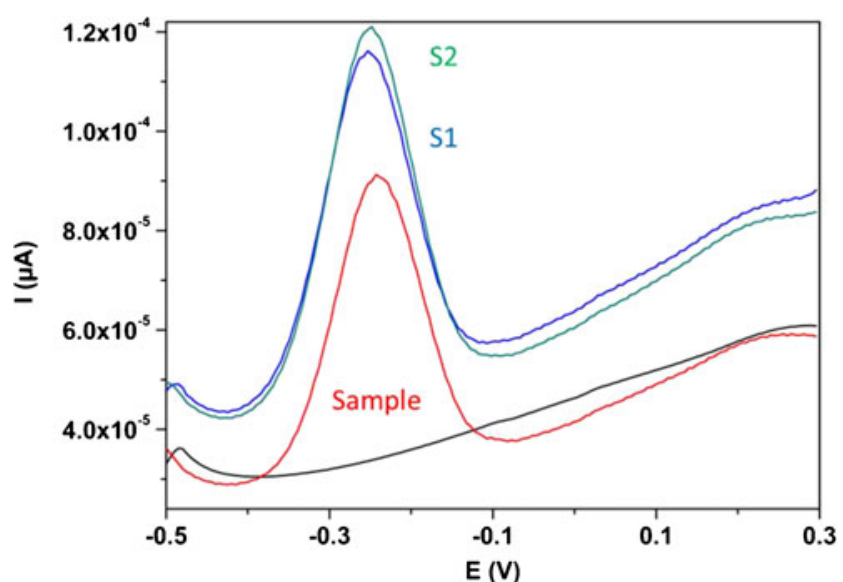

Fig. 6 DP voltammograms obtained for determination of Vitamin $B_{2}$ (S1-S2 standard addition 1 and 2) at $\mathrm{MnO}_{2} / \mathrm{CPE}$ electrode, in buffer at $\mathrm{pH} 2.0$, under optimized experimental parameters

pulse voltammetry. The observed results showed that incorporating of $\mathrm{MnO}_{2}$ in the structure of carbon paste electrode increases its affinity towards determination of riboflavin with a good reproducibility and very low detection limit. Based on the simplicity of the electrode preparation, its sensitivity and selectivity we propose simple, inexpensive electrochemical sensor which can be used for application on the field of riboflavin analysis.

Acknowledgments E.M wishes to acknowledgement Higher KOS Stipendien, financed by ADA and MEST and Austrian Agency for International Cooperation in Education and Research (OeAD-GmbH), Centre for International Cooperation \& Mobility (ICM). D.M.S. wishes to acknowledgement the Ministry of Education and Science of the Republic of Serbia (project No. OI 172030).

Compliance with Ethical Standards The author(s) declare that they have no competing interests

Open Access This article is distributed under the terms of the Creative Commons Attribution 4.0 International License (http:// creativecommons.org/licenses/by/4.0/), which permits unrestricted use, distribution, and reproduction in any medium, provided you give appropriate credit to the original author(s) and the source, provide a link to the Creative Commons license, and indicate if changes were made.

\section{References}

1. Revin SB, John SA (2012) Simultaneous determination of vitamins $\mathrm{B}_{2}, \mathrm{~B}_{9}$ and $\mathrm{C}$ using a heterocyclic conducting polymer modified electrode. Electrochim Acta 75:35-41

2. Sá SÉ, Silva SP, Jost LC, Spinelli A (2015) Electrochemical sensor based on bismuth-film electrode for voltammetric studies on vitamin B B $_{2}$ (riboflavin). Sensors Actuators B 209:423-430

3. Hua L, Yang X, Wang C, Yuan H, Xiao D (2007) Determination of riboflavin in urine and beverages by capillary electrophoresis with in-column optical fiber laser-induced fluorescence detection. J Chromatogr B 856:245-251

4. Qi H, Cao Z, Hou L (2011) Electrogenerated chemiluminescence method for the determination of riboflavin at an ionic liquid modified gold electrode. Spectrochim Acta A 78:211-215
5. Vidović S, Stojanović B, Veljković J, Prazi AL, Roglić G, Manojlović D (2008) Simultaneous determination of some watersoluble vitamins and preservatives in multivitamin syrup by validated stability-indicating high-performance liquid chromatography method. J Chromatogr A 1202:155-162

6. Wang M, Zhao L, Liu M, Lin JM (2007) Determination of riboflavin by enhancing the chemiluminescence intensity of peroxomonosulfatecobalt(II) system. spectrochim. Acta A 66:1222-1227

7. Shumyantseva VV, Bulko VT, Petushkova AN, Samenkova FN, Kuznetsova PG, Archakov IA (2004) Fluorescent assay for riboflavin binding to cytochrome P450 2B4. J Inorg Biochem 98:365-370

8. Safavi A, Maleki N, Ershadifar H, Tajabadi F (2010) Development of a sensitive and selective riboflavin sensor based on carbon ionic liquid electrode. Anal Chim Acta 674:176-181

9. Stankovic DM, Kalcher K (2015) The immunosuppressive drug rapamycin electroanalytical sensing using boron- doped diamond electrode. Electrochim Acta 168:76-81

10. Svorc L, Stankovic DM, Mehmeti E, Kalcher K (2014) Sensitive electrochemical determination of yohimbine in primary bark of natural aphrodisiacs using boron-doped diamond electrode. Anal Methods 6:4853-4859

11. Schachl K, Alemu H, Kalcher K, Jezkova J, Svancara I, Vytras K (1997) Amperometric determination of hydrogen peroxide with a manganese dioxide-modified carbon paste electrode using flow injection analysis. Analyst 122:985-989

12. Taba Z, Wang J (1991) Electrocatalysis and flow detection at a glassy carbon electrode modified with a thin film of oxymanganese species. Electroanalysis 3:215-219

13. Nie T, Xu JK, Lu LM, Zhang KX, Bai L, Wen YP (2013) Electroactive species-doped poly(3,4-ethylenedioxythiophene) films: enhanced sensitivity for electrochemical simultaneous determination of vitamins $B_{2}, B_{6}$ and $C$. Biosens Bioelectron 50:244-250

14. Qijin W, Nianjun Y, Haili Z, Xinpin Z, Bin X (2001) Voltammetric behavior of vitamin $\mathrm{B} 2$ on the gold electrode modified with a selfassembled monolayer of L-cysteine and its application for the determination of vitamin B2 using linear sweep stripping voltammetry. Talanta 55:459-467

15. Kalcher K (1990) Chemically modified carbon paste electrodes in voltammetric analysis. Electroanalysis 2:419-433

16. Tashkhourian J, Nami-Ana SF (2015) A sensitive electrochemical sensor for determination of gallic acid based on $\mathrm{SiO}_{2}$ nanoparticle modified carbon paste electrode. Mater Sci Eng C 52:103-110

17. Zbiljić J, Guzsvány V, Vajdle O, Prlina B, Agbaba J, Dalmacija B, Kónya Z, Kalcher K (2015) Determination of $\mathrm{H}_{2} \mathrm{O}_{2}$ by $\mathrm{MnO}_{2}$ modified screen printed carbon electrode during Fenton and visible light-assisted photo-Fenton based removal of acetamiprid from water. J Electroanal Chem 755:77-86

18. Wang Y, Zhuang Q, Ni Y (2015) Fabrication of riboflavin electrochemical sensor based on homoadenine single-stranded DNA/ molybdenum disulfide-graphene nanocomposite modified gold electrode. J Electroanal Chem 736:47-54

19. Nezamzadeh Ejhieh A, Pouladsaz P (2014) Voltammetric determination of riboflavin based on electrocatalytic oxidation at zeolitemodified carbon paste electrodes. J Ind Eng Chem 20:2146-2152

20. Ensafi AA, Heydari-Bafrooei E, Amini M (2012) DNAfunctionalized biosensor for riboflavin based electrochemical interaction on pretreated pencil graphite electrode. Biosens Bioelectron 31:376-381

21. Sljukic B, Compton RG (2007) Manganese dioxide graphite composite electrodes formed via a low temperature method: detection of hydrogen peroxide, ascorbic acid and nitrite. Electroanalysis 19: 1275-1280

22. Zhang L, Yuan SM, Yang LM, Fang Z, Zhao GC (2013) An enzymatic glucose biosensor based on a glassy carbonvelectrode modified with manganese dioxide nanowires. Microchim Acta 180:627-633 